\title{
Enfermidades do trato respiratório posterior em eqüinos de equitação no Rio de Janeiro: prevalência e aspectos clínico-laboratoriais
}

\section{Lower respiratory tract diseases in riding horses in Rio de Janeiro: prevalence, clinical and laboratory aspects}

\author{
Daniel Augusto Barroso Lessa, ${ }^{\star}$ Carlos Henrique Machado, ${ }^{* *}$ Carla Soares Duarte, ${ }^{* \star *}$ Lúcia Wachholz, ${ }^{* \star *}$ José Roberto P. \\ de Andrade Lima, ${ }^{* * * *}$ Wilson Roberto Fernandes ${ }^{\star * * * * *}$
}

\begin{abstract}
Resumo
Enfermidades do trato respiratório posterior em eqüinos estabulados em grandes centros urbanos são uma realidade em vários locais do mundo. Com o objetivo de verificar a prevalência e discutir aspectos clínico-laboratoriais relevantes para o diagnóstico das enfermidades do trato respiratório posterior, foram examinados 23 eqüinos, regularmente utilizados para equitação, pertencentes ao Regimento Escola de Cavalaria-Andrade Neves EB/ME/RJ, com sintomas sugestivos de doença respiratória, sendo 14 machos e 09 fêmeas, com idades variando de 03 a 22 anos e pesando entre 400 e $530 \mathrm{~kg}$. Realizaramse exame físico, endoscopia, hemograma, dosagem de fibrinogênio plasmático e citologia do lavado broncoalveolar. Considerando-se o total de animais examinados encontrou-se 4,3\% de doença pulmonar obstrutiva crônica, 8,7\% de broncopneumonias, $17,4 \%$ de doença inflamatória de vias aéreas, 47,8\% de hemorragia pulmonar induzida pelo exercício e 4,3\% de doença pulmonar indiferenciada.
\end{abstract}

Palavras-chave: eqüinos, enfermidades pulmonares, lavado broncoalveolar.

\begin{abstract}
Lower respiratory tract disease in equines kept in urban areas are a reality in several places of the world. In order to assess the prevalence and discuss clinical-laboratorial aspects that are relevant in the diagnosis of diseases of the lower respiratory tract, 23 rinding horses were analyzed. Animals were regularly used, belonged to the Regimento Escola de Cavalaria-Andrade Neves EB/ME/RJ, and presented suggestive symptoms of respiratory disease. They were 14 males and 09 females, aged 03 to 22 years old, which weighted from 400 to $530 \mathrm{~kg}$. Physical examination, endoscopy, CBC, plasma fibrinogen and bronchoalveolar lavage cytology were performed. From the total number of animals examined, $4.3 \%$ presented chronic obstructive pulmonary disease, $8.7 \%$ bronchopneumonia, $17.4 \%$ inflammatory airway disease, $47.8 \%$ exercise induced pulmonary hemorrhage and $4.3 \%$ undifferentiated pulmonary disease.
\end{abstract}

Keywords: equine, pulmonary disease, bronchoalveolar lavage.

\section{Introdução}

Enfermidades do trato respiratório posterior em eqüinos estabulados nos grandes centros urbanos são uma realidade em vários locais do mundo. Problemas respiratórios são importantes causas de prejuízo no treinamento de cavalos de corrida (Rossdale et al., 1985 e Bailey et al., 1999).

Burrell (1985) diagnosticou 47\% de hemorragia pulmonar induzida pelo exercício (HPIE) em eqüinos Puro-sangue In- glês jovens e em treinamento. Sweeney (1991), revisando vários autores, relatou uma incidência de 14 a $75 \%$ desta enfermidade para animais de corrida, $11 \%$ para os de pólo e $13 \%$ para os de Cross-Country. Na Austrália, McKane et al. (1993) observaram 90\% de HPIE em eqüinos de corrida. Dixon et al. (1995) concluíram que de 300 animais examinados 5,9\% apresentaram esta afeç̧ão. Em São Paulo, Sanches (1998) detectou 3\% de HPIE e no Jockey Club Brasileiro, Da Nova et al. (2000) detectaram $58 \%$.

\footnotetext{
* Departamento de Patologia e Clínica Veterinária, Faculdade de Veterinária, UFF, Niterói, RJ - CEP: 24230-340. E-mail: lessadab@vm.uff.br

** DMCV/IV/UFRRJ/RJ

*** Médica-veterinária autônoma/RJ

**** Médica-veterinária, Faculdade Veterinária/UFPel/RS

***** Capitão, médico-veterinário, Exército Brasileiro.

***** Clínica Médica, FMVZ/USP/SP
} 
Ainda em eqüinos Puro-sangue Inglês em treinamento, Burrell (1985) observou inflamação de vias aéreas posteriores em $50 \%$ dos animais examinados; Wood et al. (1999), em estudo epidemiológico longitudinal no Reino Unido, detectaram uma prevalência de $13,8 \%$ de doença inflamatória das vias aéreas (DIVA) e na Inglaterra, Chapman et al. (2000) verificaram que cerca de $11,3 \%$ dos aspirados traqueais examinados apresentaram alterações compatíveis com doença das vias aéreas posteriores.

Em São Paulo, Sanches (1998) detectou 1,5\% de reação alérgica por partícula inalada e no Rio de Janeiro, Lessa et al. (2002) verificaram que $60 \%$ das amostras de lavado broncoalveolar (LBA) obtidos de animais sem raça definida, utilizados para policiamento e aparentemente sadios, apresentaram quadros inflamatórios, sendo um compatível com doença pulmonar obstrutiva crônica (DPOC) e os demais (11) compatíveis com DIVA.

Na Suíça, Bracher et al. (1991) observaram que em dois grupos de eqüinos sem história clínica de enfermidade respiratória, cerca de 54\% dos animais apresentaram DPOC. Percentagem semelhante $(54,8 \%)$ desta enfermidade também foi verificada por Dixon et al. (1995) no Reino Unido. Em São Paulo, Sanches (1998) detectou 15,4\% de DPOC e no Rio de Janeiro, Amaral et al. (1999) verificaram que 60\% dos animais de policiamento apresentaram a enfermidade.

McGorum e Dixon (1994) afirmaram que broncopneumonia bacteriana e pleuropneumonia raramente afetam cavalos adultos no Reino Unido. Dixon et al. (1995) observaram 16,7\% de doença pulmonar infecciosa ou pós-infecciosa, 2,6\% de infecção pulmonar por Streptocuccus zooepidemicus e $6,7 \%$ de doença pulmonar indiferenciada. Em São Paulo, Sanches (1998) detectou 12,3\% de broncopneumonia bacteriana.

Não existe na literatura nacional estudo sobre a prevalência de enfermidades do trato respiratório, posterior em animais de equitação.

O objetivo deste trabalho foi verificar a prevalência, assim como discutir aspectos clínico-laboratoriais relevantes para o diagnóstico das enfermidades do trato respiratório posterior em eqüinos de equitação, pertencentes ao Regimento Escola de Cavalaria Andrade Neves EB/ME/RJ.

\section{Material e métodos}

Foram examinados 23 eqüinos regularmente utilizados para equitação, sendo oito garanhões, cinco machos castrados, nove fêmeas, com idades variando de três a 22 anos e pesos de 400 a $530 \mathrm{~kg}$, dos quais nove Puro-sangue Inglês, $10 \mathrm{sem}$ raça definida, dois Hanoveranos e dois Brasileiros de Hipismo, pertencentes ao Regimento Escola de Cavalaria Andrade Neves EB/ME/RJ, regularmente vermifugados com ivermectina; vacinados contra tétano, influenza e encefalomielite eqüina oeste; alimentados com ração comercial peletizada, capim verde e feno de Coast-Cross; e mantidos em cocheiras. Todos os animais apresentavam sintomas sugestivos de doença respiratória (Tabela 1).

A avaliação dos animais constou de exame físico, hemograma, dosagem de fibrinogênio plasmático, endoscopia e citologia broncoalveolar.
O hemograma e a dosagem de fibrinogênio plasmático foram realizados segundo as técnicas descritas por Coles (1984), tendo-se adotado para fins comparativos os valores de referência preconizados por Tyler et al. (1987).

Para realização da endoscopia foi utilizado um colonofibroscópio Olympus CF tipo IBW. O exame endoscópico do trato respiratório foi executado segundo a técnica descrita por Dixon (1997).

Os lavados broncoalveolares (LBA) foram obtidos infundindo-se, através de uma sonda de silicone apropriada (Equine broncho-alveolar catheter, BIVONA®), $250 \mathrm{~mL}$ de solução salina $0,9 \%$ aquecida a $37^{\circ} \mathrm{C}$, segundo a técnica descrita por Hoffman e Viel (1997).

O material aspirado foi dividido em alíquotas de cinco mililitros e centrifugado a 226 x g por cinco minutos. $O$ sedimento obtido foi ressuspenso e homogeneizado com uma gota de soro eqüino homólogo. Confeccionaram-se esfregaços que foram corados pelo método de Wright. Foram contadas 300 células à microscopia óptica de imersão, num aumento de 1000x. Adotaram-se os valores de referência de Viel (1997).

\section{Resultados e discussão}

De acordo com os exames realizados, 17 animais $(73,9 \%)$ apresentaram enfermidades do trato respiratório posterior. Enfermidades do trato respiratório anterior foram diagnosticadas em 12 animais e guturocistites em cinco. Apenas um animal (no 4) não apresentou doença respiratória. Considerando-se o total de animais examinados, encontrouse um $(4,3 \%)$ com doença pulmonar obstrutiva crônica, dois $(8,7 \%)$ com broncopneumonia, quatro $(17,4 \%)$ com doença inflamatória das vias aéreas, 11 (47,8\%) com hemorragia pulmonar induzida pelo exercício e um $(4,3 \%)$ com doença pulmonar indiferenciada (Tabela 1).

Mesmo existindo diferenças no percentual de DPOC na literatura, o valor de $4,3 \%$ verificado neste trabalho está próximo do encontrado por Lessa et al. (2002). Apesar dos sintomas sugestivos (Tabela 1), da presença de secreção mucopurulenta na traquéia e da hiperemia de carina observadas à endoscopia, a não-detecção de alterações tanto à percussão quanto à ausculta pulmonar, pode ter sido em função da ação broncoespasmolítica do Cloridrato de Clembuterol utilizado no tratamento.

A presença de espirais de Curschmann (Figura 1) foi considerada por Deconto (1984) como comprobatória de DPOC. Geralmente o LBA de animais com esta enfermidade caracteriza-se por aumento de neutrófilos (Derksen et al., 1985 e Viel, 1997). Porém, um aumento de linfócitos (Tabela 3 e Figura 1) também foi observado por Derksen et al. (1985), Freemann e Roszel (1997) e Costa et al. (2000).

Neste trabalho, a broncopneumonia correspondeu à terceira maior prevalência de enfermidades, de forma semelhante ao que já haviam relatado Dixon et al. (1995) e Sanches (1998).

Apesar de no animal $n^{\circ} 5$ os achados clínicos e endoscópicos tais como: febre, taquipnéia, tosse espontânea, rinorréia mucopurulenta, ruído broncovesicular aumentado e secreção mucopurenta na traquéia, fossem compatíveis com broncopneumonia, o resultado da citologia broncoalveolar foi normal (Tabela 3). Já o animal n¹7 apresentou, além das 
Tabela 1 - Sintomas sugestivos e respectivos diagnósticos em 23 eqüinos com suspeita de doença respiratória, Rio de Janeiro, 2003

\begin{tabular}{|c|c|c|}
\hline $\begin{array}{l}N^{\circ} \text { do } \\
\text { animal }\end{array}$ & Sintomas & Diagnósticos \\
\hline 1 & Dispnéia, estridor durante e epistaxis pós-exercício & HPIE \\
\hline 2 & Epistaxis pós-exercício & HPIE \\
\hline 3 & Rinorréia e performance insuficientes & Adenite \\
\hline 4 & Intensa dispnéia apenas durante exercício intenso & Sem doença respiratória \\
\hline 5 & Tosse & Broncopneumonia \\
\hline 6 & Tosse e rinorréia esquerda mucopurulenta & DIVA \\
\hline 7 & Queda de performance & DIVA \\
\hline 8 & Rinorréia pós prandial c/ conteúdo alimentar (ração) & Adenite, Guturocistite e HPIE \\
\hline 9 & Rinorréia catarral bilateral e linfonodos retrofaríngeos doloridos & Adenite \\
\hline 10 & Dispnéia, rinorréia mucosa branca e linfonodos submandibulares doloridos & DIVA \\
\hline 11 & Tosse e dispnéia & Adenite \\
\hline 12 & Epistaxis & HPIE e DIVA \\
\hline 13 & $\begin{array}{c}\text { Febre, tosse, rinorréia mucosa branca bilateral e linfonodos } \\
\text { submandibulares doloridos }\end{array}$ & Adenite e HPIE \\
\hline 14 & $\begin{array}{l}\text { Febre, tosse, hiporexia, rinorréia mucosa bilateral, linfonodos } \\
\text { submandibulares, retrofaríngeo e parotídeo esquerdos doloridos }\end{array}$ & Adenite e Guturocistite \\
\hline 15 & Rinorréia e linfadenomegalia submandibular esquerda e dolorida & Adenite e HPIE \\
\hline 16 & $\begin{array}{l}\text { Febre, tosse, astenia, rinorréia catarral esverdeada bilateral e linfonodo } \\
\text { submandibular direito dolorido }\end{array}$ & Adenite, Guturocistite e HPIE \\
\hline 17 & Tosse, rinorréia amarela bilateral e hiperemia da mucosa nasal & Broncopneumonia \\
\hline 18 & $\begin{array}{l}\text { Tosse, rinorréia purulenta, tumefação faríngea e parotídea bilateral, } \\
\text { linfadenomegalia submandibular e dolorida }\end{array}$ & Adenite e HPIE \\
\hline 19 & $\begin{array}{l}\text { Febre, apatia, hiporexia, ruídos pulmonares anormais, rinorréia bilateral, } \\
\text { linfonodos retrofaríngeos, parotídeos e submandibulares doloridos }\end{array}$ & Doença pulmonar indiferenciada \\
\hline 20 & Tosse e rinorréia mucopurulenta & $\begin{array}{l}\text { Processo inflamatório do trato } \\
\text { respiratório anterior }\end{array}$ \\
\hline 21 & Tosse, edema faríngeo, linfadenite retrofaríngea e submandibular & Adenite, Guturocistite e HPIE \\
\hline 22 & Linfadenomegalia submandibular, retrofarígea e parotídea & Adenite, Guturocistite e HPIE \\
\hline 23 & Emaciação, tosse crônica e estridor & NLR esquerda, HPIE e DPOC \\
\hline
\end{tabular}

Legenda: DPOC - Doença pulmonar obstrutiva crônica; DIVA - Doença inflamatória da vias aéreas; HPIE - Hemorragia pulmonar induzida pelo exercício; NLR - Neuropatia laríngea recorrente.

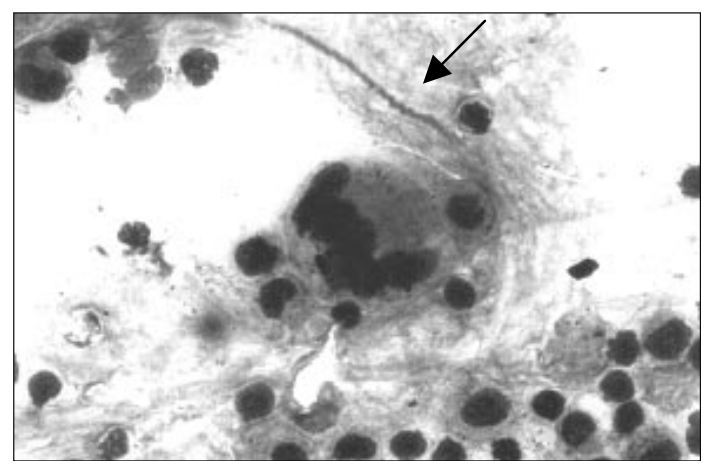

Figura 1 - Animal 23, DPOC. Predomínio de linfócitos, presença de célula gigante de corpo estranho, muco amorfo e espiral de Curschmann (seta). Wright, 1000X

alterações clínicas, endoscópicas e do leucograma (Tabela 2), quadro citopatológico compatível com a enfermidade (Tabela 3, Figura 2), à semelhança dos descritos por Rossier et al. (1991) e McGorum e Dixon (1994).

A possibilidade de resultados citológicos normais em animais com quadros broncopneumônicos também foi observada por Rossier et al. (1991). Isto decorre do fato da localização predominantemente cranioventral destes processos infecciosos e da técnica de lavado empregada neste trabalho, a qual, conforme constatado por McKane e Rose (1993), reti- ra material preferencialmente da região caudo-dorsal do pulmão. Isto significa que no animal $n^{\circ} 5$ o segmento pulmonar lavado não foi representativo, corroborando com as observações de McGorum e Dixon (1994).

O percentual de HPIE, observado neste trabalho, difere daqueles relatados por Sweeney (1991) para cavalos de pólo e Cross Country, assim como dos de McKane et al. (1993) para animais de corrida. Difere também dos percentuais descritos por Dixon et al. (1995) e por Sanches (1998), porém, assemeIha-se àqueles de Burrel (1985), Sweeney (1991) e Da Nova et al. (2000) para animais de corrida. Ainda que não se tenha verificado na literatura informações referentes a cavalos de salto, neste trabalho observou-se ser esta a principal enfermidade para os animais utilizados nesta modalidade esportiva (seis em 11 animais). A idade dos pacientes reforça a hipótese de Sweeney (1991) sobre a tendência de aumento da incidência de HPIE pelo aumento da idade, uma vez que dos 11 animais, apenas 4 ( $n^{\circ s} 13,16,18$ e 22) apresentavam idade igual ou abaixo de seis anos. Nos demais, a idade mínima observada foi de nove anos.

A constatação de hemorragia pulmonar através do LBA mesmo sem o diagnóstico endoscópico, conforme observado em todos os casos, já foi anteriormente relatada (Fogarty e Buckley 1991 e Mckane et al. 1993), fato esse que reforça a utilidade do LBA para o diagnóstico da HPIE.

Hemossiderófagos (Figura 3) indicam algum grau de hemorragia, porém sua presença pode estar ligada a outras cau- 


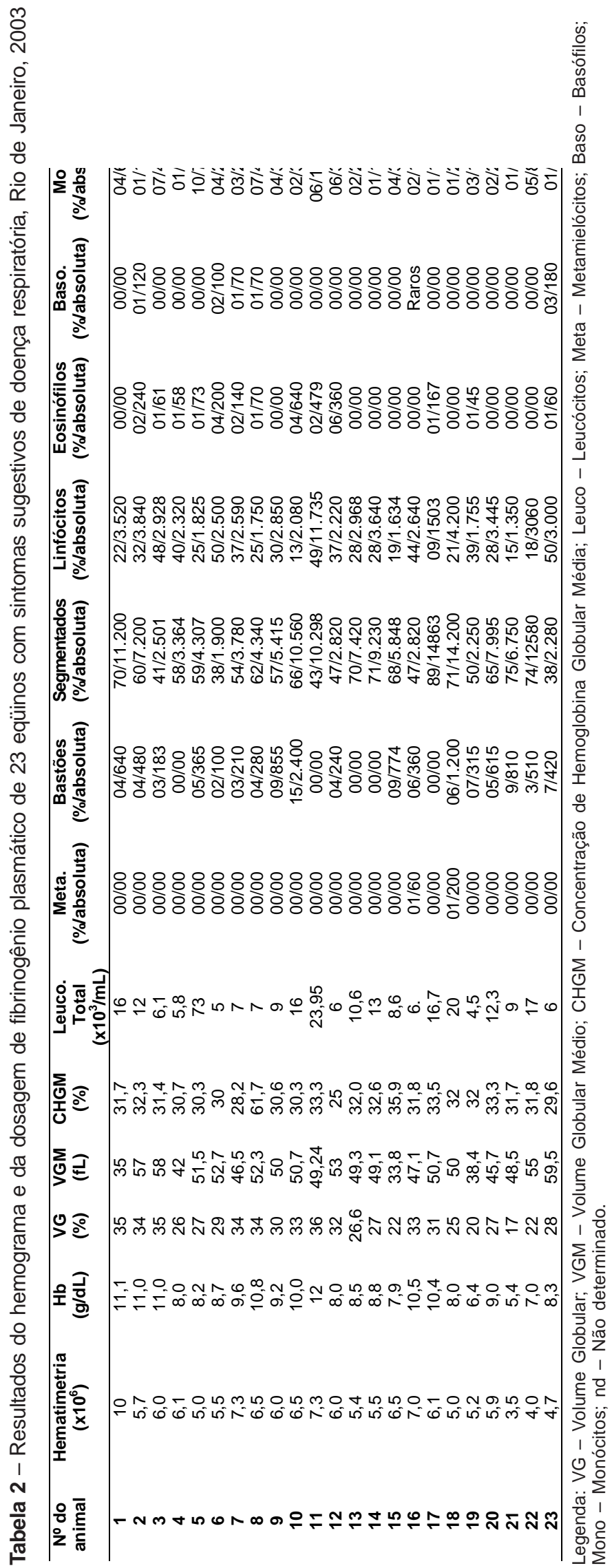

sas tais como insuficiência cardíaca com congestão pulmonar, broncopneumonias, pleuropneumonias ou pneumonia por aspiração (Roszel et al. 1988). Apesar disso, Derksen et al. (1989), Fogarty e Buckley (1991) e Mckane et al. (1993) também consideram a presença de tais células como indicativo de HPIE, mesmo em animais sem problemas de performance. O percentual de HPIE observado neste trabaIho, considerando-se a presença de hemossiderófagos, não significa que a enfermidade esteja sendo clinicamente relevante para todos os animais. Dos 11 animais considerados positivos para HPIE, três ( $n^{\circ s} 1,2$ e 12) apresentaram epistaxis. Dispnéia e queda de performance foram observadas apenas nos animais $\mathrm{n}^{\text {os }} 1$ e 7 , respectivamente (Tabela 1).

Apesar da prevalência de DIVA observada neste trabalho diferir de Burrel (1985), Sanches (1998) e Lessa et al. (2002), está próximo da relatada por Wood et al. (1999) e dos percentuais de Chapman et al. (2000).

Quanto à atividade esportiva e à idade, os resultados aqui apresentados diferem dos de Moore et al. (1995), Burrel et al. (1996) e Viel (1997), que consideraram a DIVA comum em animais jovens e de corrida. A idade dos animais com a enfermidade variou entre 10 e 20 anos, achado que corrobora com os de Hoffman (1999), Chapman et al. (2000) e Couëtil et al. (2001).

Dos quatro animais com DIVA, apenas o animal $n^{\circ} 12$ não apresentava sintomas tais como, rinorréia; dispnéia, tosse ou queda de performance (Tabela 1). Porém, animais aparentemente saudáveis podem apresentar alterações pulmonares (Burrel 1985, Sweeney et al. 1992 e Lessa et al. 2002). Todos os animais apresentaram discreto aumento da freqüência respiratória, sendo que em dois a freqüência respiratória foi maior que 20 movimentos/minuto, conforme descreveu Viel (1997).

A tosse, como indicativo de DIVA, apresenta baixa sensibilidade $(38 \%)$ e a associação entre rinorréia e a enfermidade, na ausência de tosse, não é significativa (Burrel et al. 1996). Os resultados deste trabalho corroboram com as observações acima referidas, uma vez que dos quatro animais, apenas um ( $n^{\circ}$ 6) apresentou tosse espontânea ao exame físico e nenhum deles apresentou rinorréia, e sim secreções secas nas narinas (animais nos 6,7 e 10), indicando que previamente havia ocorrido tal manifestação clínica.

Estes mesmos animais apresentaram ronco inspiratório, ruído broncovesicular aumentado e crepitações (finas e grossas), respectivamente. Estes achados divergem da opinião de Hodgson e Hodgson (2002) sobre a raridade destas alterações à ausculta pulmonar, uma vez que, dos quatro animais enfermos, em três foram detectadas alterações.

A inflamação determinada pela DIVA não se refletiu no quadro hematológico, conforme também observado por Christley (1998). A presença de secreção mucosa (animal no 07) e mucopurulenta (animais nos 6 e 10) na traquéia, detectadas à endoscopia, são compatíveis com quadros inflamatórios do trato respiratório posterior (Burrel 1985, Burrel et al. 1996, Dixon 1997 e Viel 1997).

Com relação à citologia broncoalveolar, o aumento no número de neutrófilos observado no animal $n^{\circ} 7$ (Tabela 1) corrobora com as observações de Derksen et al. (1989), Vrins et al. (1991), Moore et al. (1995), Freeman e Roszel (1997), Viel (1997), Hoffman (1999) e Ferro et al. (2002). O aumento no 
Tabela 3 - Resultados da citologia broncoalveolar em 23 eqüinos com sintomas sugestivos de doença respiratória, Rio de Janeiro, 2003

\begin{tabular}{|c|c|c|c|c|c|c|}
\hline $\mathrm{N}^{\circ}$ caso & $\begin{array}{l}\text { Neutrófilo } \\
(\%)\end{array}$ & $\begin{array}{l}\text { Linfócito } \\
(\%)\end{array}$ & $\begin{array}{l}\text { Eosinófilo } \\
(\%)\end{array}$ & $\begin{array}{l}\text { Macrófago } \\
(\%)\end{array}$ & $\begin{array}{l}\text { Mastócito } \\
(\%)\end{array}$ & Obs. \\
\hline 1 & 2,6 & 23,4 & 0,0 & 73,8 & 0,2 & Cor castanha/hemossiderófagos (+++) \\
\hline 2 & 6,8 & 27,8 & 0,2 & 65,2 & 0,0 & hemossiderófagos $(+)$ \\
\hline 3 & 2,6 & 27,4 & 0,0 & 70,0 & 0,0 & \\
\hline 4 & 1,8 & 75,4 & 0,2 & 21,8 & 0,8 & \\
\hline 5 & 3,2 & 59,8 & 1,4 & 34,0 & 1,6 & hemossiderófagos (+) \\
\hline 6 & 4,0 & 52,0 & 3,6 & 40,3 & 0,0 & \\
\hline 7 & 13,3 & 77,3 & 0,6 & 7,6 & 1,0 & \\
\hline 8 & 3,6 & 17,0 & 1,6 & 76,6 & 1,0 & hemossiderófagos (+) \\
\hline 9 & 4,3 & 56,0 & 0,3 & 38,3 & 1,0 & \\
\hline 10 & 0,6 & 71,3 & 15,6 & 11,3 & 1,0 & Amarelado \\
\hline 11 & 1,3 & 42,0 & 0,3 & 56,3 & 0,0 & \\
\hline 12 & 4,0 & 60,0 & 8,3 & 26,0 & 1,6 & Amarelado/hemossiderófagos (raros) \\
\hline 13 & 2,0 & 34,0 & 0,6 & 51,6 & 1,6 & hemossiderófagos (raros) \\
\hline 14 & 0,0 & 57,3 & 0,6 & 41,0 & 1,0 & \\
\hline 15 & 1,3 & 64,3 & 0,3 & 33,0 & 1,0 & Raros hemossiderófagos e Macrófagos espumosos \\
\hline 16 & 0,3 & 18,3 & 0,0 & 81,3 & 0,0 & hemossiderófagos $(+)$ e raras células. gigantes \\
\hline 17 & 32,6 & 24,0 & 0,0 & 43,3 & 0,0 & $\begin{array}{l}\text { Castanho claro/hemossiderófagos (++), células. } \\
\text { gigantes (+) Macrófagos espumosos (+++) }\end{array}$ \\
\hline 18 & 2,0 & 35,3 & 0,0 & 62,6 & 0,0 & hemossiderófagos (+) \\
\hline 19 & 0,3 & 83,3 & 0,0 & 16,3 & 0,0 & Raros Macrófagos espumosos \\
\hline 20 & 1,0 & 38,3 & 0,3 & 59,6 & 0,6 & Macrófagos espumosos (++) \\
\hline 21 & 3,6 & 47,3 & 0,3 & 48,3 & 0,3 & Raros hemossiderófagos/Macrófagos espumosos (++) \\
\hline 22 & 3,3 & 32,0 & 0,0 & 63,6 & 1,0 & Raros hemossiderófagos e célulass. gigantes \\
\hline 23 & 4,3 & 59,0 & 0,0 & 31,0 & 2,3 & $\begin{array}{c}\text { Ausência de surfactante e hemossiderófagos }(+) \text { e } \\
\text { espirais de Curshman }\end{array}$ \\
\hline
\end{tabular}

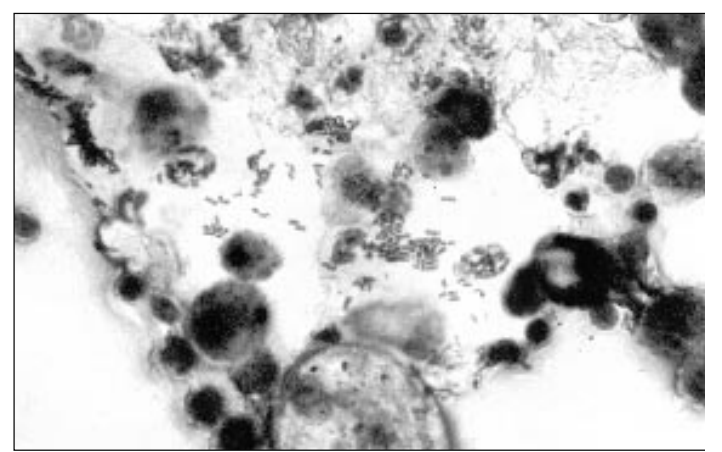

Figura 2 - Animal 17, broncopneumonia. Presença de macrófagos, hemossiderófagos, neutrófilos, bactérias, muco amorfo e debris celulares. Wright, $1000 \mathrm{X}$

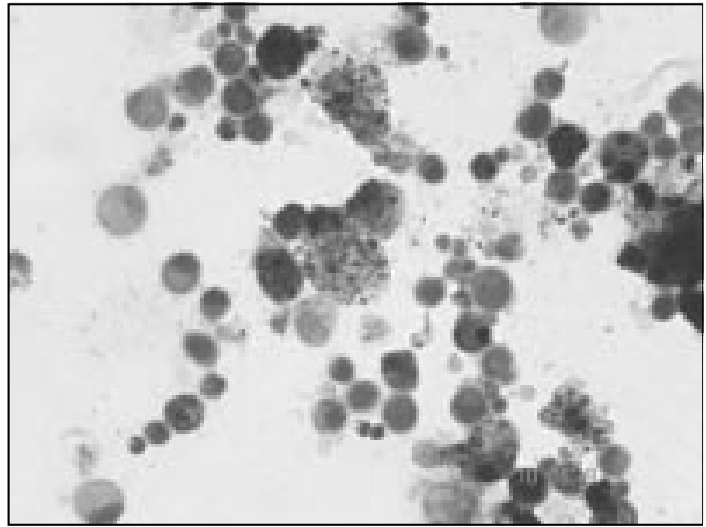

Figura 3 - Animal 1, HPIE, predomínio de macrófagos e linfócitos, presença de hemossiderófagos e hemossiderina livre. Wright, 400X

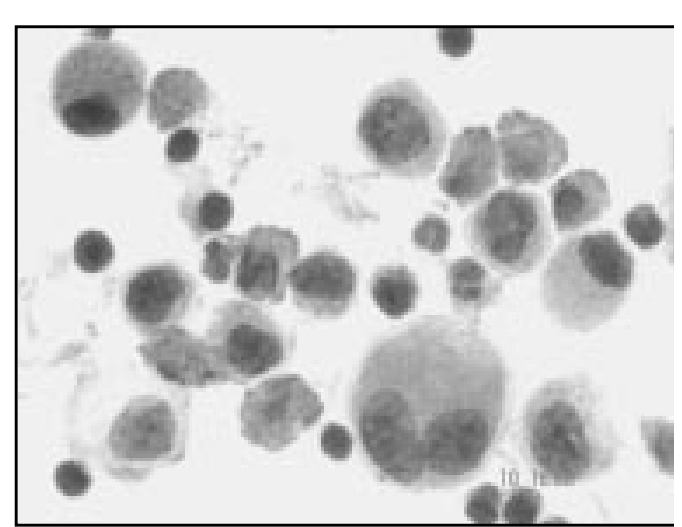

Figura 4 - Animal 10, DIVA, presença de macrófagos, linfócitos, neutrófilo e grande número de eosinófilos. Wright, $1000 \mathrm{X}$ 
número de eosinófilos (Tabela 3) foi um achado característico para os animais de nos 6,10 (Figura 4) e 12, fato também descrito por Derksen et al. (1989), Moore et al. (1995), Viel (1997), Freeman e Roszel (1997) e Ferro et al. (2002). Tal característica também pode ser compatível com pneumonite parasitária. Porém Hare e Viel (1998) não consideram que esses quadros em animais encocheirados, sem acesso a pastagens e regularmente desverminados, conforme a situação dos animais deste estudo, possam ser compatíveis com essa enfermidade. Além disso, quadros citopatológicos de pneumonite parasitária apresentam "debris" necróticos (Freeman e Roszel 1997), fato que também não foi evidenciado nestes animais.

O percentual observado neste trabalho para doença pulmonar indiferenciada (animal $n^{\circ} 19$, Tabela 1) está próximo do verificado por Dixon et al. (1995). Os sintomas (Tabela 1), assim como os achados ao exame físico, tais como: taquipnéia, dispnéia, rinorréia mucopurulenta, sinais flogísticos no trato respiratório anterior e crepitações finas no pulmão esquerdo, permitem suspeitar de processo inflamatório infeccioso, tanto anterior quanto posterior. Porém, o animal apresentou normotermia e resultados de leucograma e de fibrinogênio plasmático (Tabela 2) dentro da normalidade. Ainda que isto seja possível (Tyler et al. 1987), provavelmente ocorreu em função da antibioticoterapia à base de penicilina, que interferiu no curso da enfermidade.

Como neste animal as crepitações foram auscultadas principalmente na área crânio-ventral pulmonar e o aumento de linfócitos observado no LBA (Tabela 3) não é característico de quadros broncopneumônicos, pode-se inferir que a amostra de lavado pode não ter sido representativa, à semelhança do que ocorreu no animal $n \div 5$. Outras possibilidades para tal fato são: o quadro citopatológico observado ter evidenciado um momento da dinâmica inflamatória pulmonar sem aumentos no número de neutrófilos ou ter ocorrido interferência terapêutica. Levando-se em conta os achados clínicolaboratorias e a falta de resultado endoscópico, classificouse este caso como doença pulmonar indiferenciada, segundo os critérios de Dixon et al. (1995).

Apesar de o animal nํ 4 apresentar dispnéia (Tabela 1), não foi detectada ao exame físico e endoscópico, qualquer outra alteração compatível com doença respiratória. Porém, os resultados do hemograma (Tabela 2) permitem concluir que tal manifestação estava relacionada com a anemia normocítica hipocrômica.

\section{Conclusões}

Diante dos achados conclui-se que:

Apesar de clinicamente a DPOC e a DIVA serem semelhantes, a prevalência detectada neste trabalho para estas enfermidades diferiu da expectativa prévia dos autores, sendo também a primeira descrição, no Brasil, de DIVA em animais mais velhos e de equitação.

Ainda que a HPIE seja notoriamente relevante para animais de corrida, a prevalência desta enfermidade em animais de equitação, particularmente de salto, chama a atenção, uma vez que não se verificam relatos anteriores para esta modalidade esportiva.

Mesmo tendo sido verificados apenas dois animais com broncopneumonia, eles corresponderam a quase $10 \%$, o que não pode ser considerado raro.

\section{Agradecimentos}

Aos oficiais médicos-veterinários e ao Comando do Regimento Escola de Cavalaria Andrade Neves (EB/ME/Brasil), por permitir a utilização de seus animais neste trabalho.

\section{Referências}

AMARAL, P. C.; GRAÇA, F. A. S.; VIANNA, L. F. C. G.; BORGES, J. R. J.; FERREIRA, A. M.; PIRES, N. R.; VOSS, C. Doença pulmonar obstrutiva crônica em eqüinos da Polícia Militar do Estado do Rio de Janeiro. Revista Brasileira de Ciência Veterinária, v. 6, n. 2, p. 77-83, 1989. BRACHER, V.; FELLENBERG, R. VON; WINDER, C. N.; GRUENIG, G.; HERMANN, M.; VON-FELLENBERG, R. An investigation of the incidence of chronic obstructive pulmonary disease (COPD) in random populations of Swiss horses. Equine Veterinary Journal, v. 23, n. 2, p. 136-141, 1991.

BAILEY, C. J.; REID, S. W. J.; HODGSON, D. R.; ROSE, R. J. Impact of injuries and disease on a cohort of two- and three-year-old thoroughbreds in training. The Veterinary Record. v. 145, p. 487-493, October 1999.

BURREL, M. H. Endoscopic and virological observations on respiratory disease in a group of young thoroughbred horses in training. Equine Veterinary Journal, v. 17, n. 2, p. 99-103, 1985.

BURREL, M. H.; WOOD, J. L. N.; WHITWELL, K. E.; CHANTER, N.; MACKINTOSH, M. E.; MUMFORD, J. A. Respiratory disease in thoroughbred horses in training: the relationships between disease and viruses, bacteria and environment. The Veterinary Record. v. 139, p. 308-313, September 1996.
CHAPMAN, P. S.; GREEN, C.; MAIN, J. P. M.; TAYLOR, P. M.; CUNNINGHAM, F. M. Retrospective study of the relationships between age, inflammation and isolation of bacteria from the lower respiratory tract of thoroughbred horses. The Veterinary Record. v. 146, p. 9195, January 2000.

CHRISTLEY, R. M. Studies of the epidemiology of respiratory disease in Thoroughbred racehorses in Sydney, Australia, 1998. PhD Dissertation, University of Sydney, 1998 (citado por Hodgson \& Hodgson 2002).

COLES, E. H. Patologia clínica veterinária. 3. ed. São Paulo: Manole, 1984. 566p.

COSTA, R.. L. R.; SEAHORN, T. L.; MOORE, R. M.; TAYLOR, H. W.; GAUNT, S. D.; BEADLE, R. E. Correlation of clinical score, intrapeural pressure, cytologic findings of bronchoalveolar fluid, and histopatologic lesions of pulmonary tissue in horses with summer pasture-associated obstructive pulmonary disease. American Journal of Veterinary Research, v. 61, n. 2, p. 167-173, February 2000.

COUËTIL, L. L.; ROSENTHAL, F. S.; DeNICOLA, D. B.; CHILCOAT, C. D. Clinical signs, evaluation of brochoalveolar lavage fluid, and assessment of pulmonary function in horses with inflammatory respiratory disease. American Journal of Veterinary Research, v. 62, n. 4, p. 538-546, April 2001. 
Da NOVA, C. A. B.; AMARAL, P. C.; PITOMBO, C. A. P.; RIBEIRO, L. C. G. Ocorrência de hemorragia pulmonar induzida pelo exercício (HPIE) no Jockey Club Brasileiro. Revista Brasileira de Medicina Veterinária, v. 7, suplemento, p. 228, 2000.

DECONTO, I. Novos conhecimentos nos exames citológicos da secreção traqueobronquial de cavalos com doenças pulmonares crônicas. I, II e III Jornadas Boehringer de Patologia Eqüina. p. 29-32, 1984.

DERKSEN, F. J.; SCOTT, J. S.; MILLER, D. C.; SLOCOMBE, R. F.; ROBINSON, N. E. Bronchoalveolar lavage in ponies with recurrent airway obstruction (Heaves). Am. Rev. Respir. Dis. v. 132, p. 10661070, 1985.

DERKSEN, F. J.;BROWN, C. M.; SONEA, I.; DARIEN, B. J.;ROBINSON, N. E. Comparison of transtracheal aspirate and bronchoalveolar lavage cytology in 50 horses with chronic lung disease. Equine Veterinary Journal, v. 21, n. 1, p. 23-26, 1989.

DIXON, P. M.; RAILTON, D. I.; McGORUM, B. C. Equine pulmonary disease: a case control study of 300 referred cases. Part 1: Examination techiniques, diagnostic criteria and diagnoses. Equine Veterinary Journal, v. 27, n. 6, p. 416-421, 1995.

DIXON, P. M. Ancillary diagnostic techniques for the investigation of equine pulmonary disease. Equine Veterinary Education, v. 9, n. 2, p. 72-80, 1997.

FERRO, E.; FERRUCCI, F.; ZUCCA, E.; DI FABIO, V.; CASTOLDI, S. Arterial blood gas analysis in 53 racehorses with diagnosis of small airway inflammatory disease (SAID). Journal of Equine Veterinary Science, v. 22, n. 4, p. 165-168, 2002.

FOGARTY, U.; BUCKLEY,T. Bronchoalveolar lavage findings in horses with exercise intolerance. Equine Veterinary Journal, v. 23, n. 6, p. 434-437, 1991.

FREEMAN, K. P.; ROSZEL, J. F. Equine cytology patterns in respiratory conditions of noninfectious or unknown origin. Comp. Cont. Educ. Pract. Vet., v. 19, n. 6, p. 755-763, June 1997.

HARE, J. E.; VIEL, L. Pulmonary eosinophilia associated with increased airway responsiveness in young racing horses. J.Vet. Intern. Med., v. 12, p. 163-170, 1998.

HODGSON, J. L.; HODGSON, D. R. Inflammatory Airway Disease. In: LEKEUX, P. ed. Equine Respiratory Disease. Intenational Veterinary Information Service, Ithaca, NY, 2002. Disponível em:<http:www.ivis.org>. Acesso em: 11 set. 2003.

HOFFMAN, A. M. Bronchoalveolar lavage technique and cytological diagnosis of small airway inflammatory disease. Equine Veterinary Education, v. 11, n. 6, p. 330-336, 1999.

HOFFMAN, A. M.; VIEL, L. Techniques for sampling the respiratory tract of horses. Veterinary Clinics of North America: Equine Practice, Philadelphia, v. 13, n. 3, p. 463-475, December 1997.

LESSA, D.A. B.; VIANA, E. B.; ABRAMOVITC, G.; PAIVA, V. S.; FERNANDES, W. R. Aspectos citológicos do lavado broncoalveolar de eqüinos da Polícia Militar do Estado do Rio de Janeiro. In: Congresso Brasileiro de Medicina Veterinária, 2002, Gramado. Anais do
Congresso Brasileiro de Medicina Veterinária. Gramado, 2002. CDROM.

McGORUM, B. C.; DIXON, P. M. The analysis and interpretetaion of equine bronchoalveolar lavage fluid (BALF) cytology. Equine Veterinary Education, v. 6, n. 4, p. 203-209, 1994.

McKANE, S. A.; ROSE, R. J. Radiographic determination of the location of a blindly

passed bronchoalveolar lavage catheter. Equine Veterinary Education, v. 5, n. 6, p. 329-332, 1993.

McKANE, S. A.; CANFIELD, P. J.; ROSE, R. J. Equine bronchoalveolar lavage cytology: survey of thoroughbred racehorses in training. Australian Veterinary Journal, v. 70, n. 11, p. 401-404, November 1993. MOORE, B. R.; KRAKOWKA, S.; ROBERTSON, J. T.; CUMMINS, J. M. Cytologic evaluation of bronchoalveolar lavage fluid obtained from Standardbred racehorses with inflamatory airway disease. American Journal of Veterinary Research, v. 56, n. 5, p. 562-567, May 1995.

ROSSDALE, P. D.; HOPES, R.; WINGFIELD DIGBY, N. J. OFFORD, K. Epidemiological study of wastage among racehorses 1982 and 1983. The Veterinary Record, v. 116, p. 66-69, January 1985.

ROSSIER, Y.; SWEENEY, C. R.; ZIEMER, E. L. Bronchoalveolar lavage fluid cytologic findings in horses with pneumonia or pleuropneumonia. Journal American Veterinary Medical Association, v. 198, n. 6, p. 1001-1004, March 1991.

ROSZEL, J. F.; FREEMAN, K. P.; SLUSHER, S. H.;MORRIS, W. R.; HAURY, K. D.; CUDD, T. A. Siderophages in pulmonary cytology specimens from racing and non-racing horses. In: Proc $33^{\text {rd }}$ Annu Conv AAEP, p. 321-329, 1988.

SANCHES, A. Avaliação citológica do lavado traqueobrônquico de eqüinos clinicamente sadios e daqueles portadores de afecções do sistema respiratório. São Paulo, SP, 1998. Dissertação de Mestrado, Universidade de São Paulo, 1998.

SWEENEY, C. R. Exercise-Induced Pulmonary Hemorrhage. Veterinary Clinics of North America: Equine Practice, v. 7, n. 1, p. 93-104, April 1991.

TYLER, R. D.; COWELL, R. L.; CLINKENBEARD, K. D.; MacALLISTER, C. G. Hematologic values in horses and interpretation of hematologic data. Veterinary Clinics of North America: Equine Practice, v. 3, n. 3, p. 461-484, 1987.

VIEL, L. Small airway disease as a vanguard for chronic obstructive pulmonary disease. Veterinary Clinics of North America: Equine Practice, v. 13, n.3, p. 549-560, December 1997.

WOOD, J. L. N.; NEWTON, J. R.; CHANTER, N.; MUMFORD, J. A.; TOWNSEND, H. G. G.; LAKHANI, K. H.; GOWER, S. M.; BURREL, M. H.; PILSWORTH, R. C.;SHEPHERD,M.;HOPES, R.;DUGDALE, D.; HERINCKX, B. M. B.; MAIN, J. P. M.;WINDSOR, H. M.;WINDSOR, D. G. A longitudinal epidemiological study of respiratory disease in racehorses: disease definition, prevalence and incidence. In: Wernery U, Wade JF, Mumford, JA, et al. (Ed.). Equine Infectious Diseases VIII. Newmarket: R \& W Publications Ltd, 1999; p. 64-70. 